in a less marked degree; in the other vertebræe of the neck. This tubercle is placed in front of the transverse process, and is the more prominent as the individual is advanced in age; it varies considerably, both in size and form, in some subjects being nothing but a simple osseous slip; in others forming a perfect hook, with the concavity turned forward. This process corresponds with the primary carotid artery, which is placed in front, and a little to the inner side of it, and furnishes so certain a guide to the vessel, that by placing a finger on the eminence, we may plunge a scalpel into the artery with the eyes shut, without any previous incision. In consequence of this connexion, M. Chassaignac has given it the name of carotid tubercule. The process can be easily felt through the integuments, at least in the dead body, being only covered by the skin, subcutaneous muscle, cervical fascia, and exterior edge of the sterno-cleidomastoid muscle. To find it, we have merely to extend the neck slightly, and press the finger on the inner edge of the above-mentioned muscle, two inches above the clavicle; at the same time we should be careful that the neck is perfectly straight, for the least rotation is enough to alter the relations between the artery and tubercle. In the living body the process is not so easily discovered, in consequence of the greater resistance given by the subcutarieous and sterno-mastoid muscles.

In an anatomical point of view, the tubercle, of which we speak, serves to distinguish the sixth cervical vertebra from all the others, and to determine in a positive manner the situation of different organs in the cervical region. As applied to surgery, a knowledge of this process may serve to direct us with the greatest certainty to the primitive carotid, and in this respect is analogous to the osseous tubercle on the first rib, close to the edge of the subclavian artery. It also presents a surface well fitted as a point d'appui to compress the ressel in cases of sudden hemorrhage. In the case of a penetrating wound, with hemorrhage, inflicted in the neighbourhood of this process, the blood may come either from the primary carotid, from the inferior thyroid, from the vertebral artery, or from the posterior or ascending cervical branches. 'The relations of these different arteries with the process in question may serve to determine the precise source of the hemorrhage, a question otherwise extremely difficult to resolve. It is immediately below this process that the vertebral artery penetrates into the canal of the cervical rertebra; the posterior cervical is below, and a little external to it; the inferior thyroid, crossing behind the carotid artery to gain the thyroid body, is also very close to it; the tubercle will, therefore, serve as a useful point de depart for the exploration of the surgeon when about to apply one or more ligatures. Should any difficulty be experienced in seeking this tubercle through the integument, it is immediately obviated by a division of the skin and superficial layer of tissue.

PRESERVATION OF SUBJECTS FOR

\section{DIS SECTION.}

TREATMENT OF DISSECTION WOUNDS.

\section{To the Editor of The LANCET.}

Sir,-In your last number, you mentioned the strong antiseptic qualities of charcoal powder, and its consequent power in reproving the stench connected with dissection. As the warm weather has now commenced, and the scalpel will, I hope, be liberally used in the dissecting. rooms this summer, it may be of utility to state that I find nothing so effectual in preventing putrescency as injecting the veins* with a strong solution of nitre and common salt. If used warm, before arteries are injected with the wax and tallow, it preparatorily increases the temperature of the body. This is much better than scattering salt or any other antiseptic over the dissection, which must necessarily obscure, if not derange, the parts. The plan I have mentioned preserves the pearly whiteness of the tendons, and often improves the colour of muscles. I have seen the latter, after having been in the dissecting-room three or four weeks, when cut into, as red as christmas beef in the shambles. Another recommendation is, that should the dissector cut his finger, the stimulus of the salt seems to couriteract the effects of the impregnating matter: Out of the numerons instances of my pupils who have cut themselves, I have not known a troublesome case, save one, where there was palpable neglect. $\mathrm{My}$ invariable advice to the student who cuts himself is, to wash the part for ten minutes with soap and warm water, then to suck the cut well for the same length of time, and, lastly, defend it conpletely by surrounding it with several turns of straps of adhesive plaster, so as to perfectly intercept the wounded finger from all adventitious matter, when the student may im-

* Mr. Frowhes need to inject a solntion of nitre alone into the a! teides. Thus is not so vell, because it obsitucted the progress of the sax. 
mediately renew, if he chooses, his dissection, again, with impunity. In every case where the above plan has been adopted, no sensible degree of local inflammation has succeeded, and no bad effects whatever have been produced.

In some neglected cases a great deal of pain is often produced by a collection of a very small quantity of matter under the aponeurosis of the finger, which, if not let out, will be probably succeeded by enlarged axillary glands and more extensive symptoms of irritation. I know the presence of matter has been denied by many, but my experience has proved that as soon as an exit was made for it, the intolerable pain has at once ceased. This was remarkably so in the troublesome case already alluded to. This pupil I took to a consulting surgeon of high repute, and proposed to him that an opening should be made, with which he did not coincide, alleging that no matter was present. In the night, however, the pain became so intolerable that $I$ was induced to do it; a small quantity of matter escaped, and the patient was instantaneously and permanently relieved from pain.

Yours very obediently, G. D. DermotT.

35, Dean-street, Soho.

PLBLIC EXPOSURE OF CHILDREN WITH THE SMALL-POX.

\section{To the Editor of Thr Lancer.}

SiR,-I observe in the last number of your Journal, a letter from a correspondent signed $M$. $M$. on inoculation, wherein he confesses himself to be not well acquainted with the subject of medical jurisprudence, yet justly complains of a parish surgeon introducing the smallpox in the neighbourhood near where he resides. If you think that the information I bere forward can serve his case, may $I$ ask the favour of its insertion in your next number?

From the relation of the following cases, which are to be found in Maule and Selwrn's Reports, it is cvident that inoculation under the circumstances he relates in his letter is unlawful. It is in their book said to be unlawful and injurious to carry a child infected with small-pox along a public highway in which persons are passing, and near to the habitations of the King's subjects, and it is an indictable offence, as the following cases evince. Some years ago two trials took place in the Court of King's Bench; one, of the mother of a child infected with the small. pox, and the wife of a journeyrnan coachmaker named Vantandillo, then residing in a court near Long-Acre, for exposing and taking the child in a diseased state of small-pox through the public streets to the house of the surgeon who inoculated it, by which the contagion infected most of the children in the court where she resided.

The second case emerged from the fore. going (if my recollection is correct). - Burnett, a surgeon-apothecary, was tried and found guilty in the King's Bench, for unlawfully advising and allowing a child to be brought through the public streets in a state of disease to his residence. So it appears to be an indictable offence in an apothecary, after having inoculated children, unlawfully and injuriously to cause them to be exposed in the public streets to the danger of public health. The learned judge (Le Blanc), in passing sentence on the defendant in this case, observed that the in. troduction of vaccination did not render the practice of inoculating for the smallpox unlawful, but that at all times it was unlawful and an indictable otfence to expose persons infected with contagious disorders liable to be communicated to the public, and injurious to the public health. The defendant was sentenced to six months imprisonment.

$\Lambda$ case under similar circumstances was tried some terms subsequent to the above trials. Mr. Ridont, of Paternoster-row, was, in this instance, found guilty, but was not called up for judgment, on a promise to discontinue the practice.

$$
\begin{aligned}
& 1 \text { remain, Sir, } \\
& \text { Yours, \&c., } \\
& \text { W. W WLFORD. }
\end{aligned}
$$

Church Row, Limehouse, May 11,1834 .

\section{To the Editor of THE LANCET.}

Sin,-The surgeon referred to by $M . M$. is punishable by indictment, not for inoculating children with small-pox, but for ordering them to be brought for inspection. - The decision of Mr. Justice Bailey, the Royal Jennerian Socicty and London Vaccine Institution publish every year in their yearly report; I beg to inclose it.

Believe me yours, \&c., JoHN Epps, M.D.,

Director of the Royal Jennerien and London Vaccine Institution.

89, Great Russell Stree

May 13, 1834. 